\title{
Displacements of shell in soil-steel bridge subjected to moving load: determination using strain gauge measurements and numerical simulation
}

https://doi.org/10.2478/sgem-2021-0028

received April 23, 2021; accepted October 4, 2021.

\begin{abstract}
This paper analyses displacements of a shell in a soil-steel bridge subjected to quasi-static moving loads. The considerations relate to a largespan structure located in Ostróda, Poland. In particular, shell displacements during a loading cycle consisting of consecutive passages of a pair of trucks over the bridge are investigated. The results of a full-scale test, that is, the readings from a system of strain gauges arranged along the shell circumferential section, are the basis for determination of shell displacements. The proposed algorithm makes it possible to calculate any component of the displacement using just a simple model of the shell in the form of a linear elastic curvilinear beam. The approach uses real measurements, and thus, it yields results of displacements reflecting the actual mechanical behaviour of the entire composite structure including not only the shell, but also the backfill, the pavement, etc. The calculated state of displacement sets the basis for calibration of the numerical model. Finite element (FE) analyses include staged construction, that is, backfilling the shell by placing successive soil layers, as well as the loading test with the vehicles moving over the bridge. It is demonstrated that the ballasting of the shell during backfilling contributes to the improvement of the simulated behaviour of the object at the stage of operation, that is, when subjected to moving truck load. Thus, the calibration of the FE model is successfully carried out using the results of strain gauge measurements.
\end{abstract}

\footnotetext{
*Corresponding author: Szczepan Grosel, Faculty of Civil Engineering, Wroctaw University of Science and Technology, Wrocław, Poland, E-mail: szczepan.grosel@pwr.edu.pl, ORCID:0000-0002-3064-454X

Czesław Machelski, Faculty of Civil Engineering, Wroctaw University of Science and Technology, Wroctaw, Poland, ORCID:0000-0002-1215-7908

Maciej Sobótka, Faculty of Civil Engineering, Wrocław University of Science and Technology, Wroctaw, Poland, ORCID:0000-0001-5166-9060
}

Keywords: soil-steel structure; moving load; strain gauge.

\section{Introduction}

The advantages of soil-steel structures, such as low consumption of expensive materials, short construction time and lack of expansion joints, have resulted in undoubted interest in this technology in recent years (Wadi, 2019). Therefore, the development of investigative methods related to this type of structures can be observed. Increasing use of soil-steel composite bridges entails extensive research on their response to static loads (e.g. Bayoglu Flener, 2010), dynamic loads (Bayoglu Flener and Karoumi, 2009; Mellat et al., 2014; Bęben 2013) and seismic excitation (e.g. Maleska and Bęben, 2021; Maleska et al., 2021). Another important aspect from a practical point of view is the analysis of the mechanical behaviour of the structure in the construction phase when the stress level in the shell is usually greater than during the operation of the completed object (Wysokowski and Janusz, 2007). Recently conducted research also concerns the assessment of the bearing capacity of soil-steel bridges (Brachman et al., 2010; Barkhordari and Abdel-Sayed, 2001). More specifically targeted studies deal with the influence of groundwater on the behaviour of the structure (Eydżba et al., 2017) or the use of soil-steel structures on sloping terrain (Wadi et al., 2015). Both real-scale tests and theoretical analyses based on numerical models are commonly used as research tools in the investigation areas mentioned above (Pettersson et al., 2015).

The most reliable sources of knowledge about the mechanics of soil-steel composite bridges are full-scale tests. They allow one to determine the behaviour of this type of engineering structures which differ in many aspects from other types of bridge structures. Most often, displacements of selected points in the shell are measured. For this purpose, after installing the markers, geodetic measurements are made, or, after the construction of 
appropriate scaffolding, displacements are measured with dial gauges. Both methods, apart from the need to fix the proper markers, have their limitations related inter alia to the time needed to perform the reading. Furthermore, such readings usually refer to small displacement values. This affects the accuracy of the measurements. Even a slight shift of the measuring base, which is very likely under field test conditions, can disrupt the results. Another commonly used measurement method is the use of strain gauges. They allow the unit strain increments to be measured continuously (in time). The interpretation of the results of the strain gauge measurements is most often boiled down to the estimation of internal forces. However, this requires the use of at least two sensors in a selected section of the shell: one in the valley and one in the crest of the corrugation. The bending moment and the axial force can be determined from Euler-Bernoulli beam theory. In Machelski and Janusz (2017), an algorithm is proposed to calculate shell displacements based on measurements from strain gauges. For this purpose, a collocation algorithm has to be used. Although the main advantage of this algorithm lies in the small number of sensors required, a two-dimensional (2D) model of the entire structure is required. Such a model must include not only a section of the shell, but also the backfill, the pavement and the surface load. Increasing the number of measurement sensors and the application of the algorithm presented in the paper allows to eliminate difficulties and inaccuracies that may occur during model creation and calculations. This work presents such an algorithm. The displacements of a steel shell are calculated using the Maxwell-Mohr integration formula without the need for a complicated collocation method. This algorithm requires more sensors to estimate unit strain functions over the entire length of the steel shell, but the calculations demand much less effort compared to the approach presented in Machelski and Janusz (2017). The necessary model comprises only a linear elastic curvilinear beam.

Although full-scale tests provide us with the most reliable practical knowledge on the actual behaviour of soil-steel composite bridges, theoretical models are necessary for design purposes. Furthermore, with appropriately accurate models, we are able to design larger and larger structures and more and more effectively use the construction materials. Models that reflect well the actual behaviour of real structures may be useful for parametric analyses in order to select the optimal shape of the shell (Sobótka, 2020), backfill cover (AbdelSayed and Salib, 2002; Esmaeili et al., 2013) or other design parameters (Machelski and Antoniszyn, 2005). The application of advanced numerical analysis can contribute to a reduced consumption of steel or concrete, and therefore to large financial savings (Maleska and Bęben, 2019). As emerges from the works published so far, the most important modelling challenges include the need to take into account the construction phases (Kunecki, 2014), frictional interface model at the contact of the steel shell with the soil backfill (Sobótka, 2014) and the appropriate constitutive relations of the latter. Since the backfill soil is a plastic material by nature (Sobótka and Eydżba, 2019), the mechanical behaviour of soilsteel composite bridges differs from the linear elastic one, often adopted, for example, for steel structures. The performance of the soil-steel composite bridge is determined by creating an appropriate interaction between the shell and the surrounding soil medium. This interaction results from the backfilling process that should be carried out properly. In a properly constructed object, the effect of shell pre-tensioning is achieved. As a result of backfilling, the key point of the shell is uplifted. Then, under the action of the operational loads, this uplift is reduced. At the same time, the stress in the shell is reduced as well. The importance of this issue is reflected in numerous works devoted to the analysis of behaviour of the shell during backfilling (e.g. Kunecki, 2014; Maleska and Bęben, 2019; Mańko and Bęben, 2005; Pittino and Golser, 2006; Taleb and Moore, 1999). The behaviour of flexible soil-steel bridges under moving load shows the so-called hysteresis effect (Sobótka, 2014; Machelski, 2014). During the passage of a vehicle over the bridge followed by its return, a distinct hysteresis loop is observed for any of the shell displacements (e.g. Sobótka, 2014; Sobótka and Machelski, 2016). However, after such a loading cycle, the deformation of the shell brings back to its initial state (Machelski, 2014). The above-mentioned features shall be taken into account when modelling the behaviour of soil-steel composite bridges. In addition to the detailed simulation techniques developed in previous papers (Eydżba et al., 2017; Sobótka, 2020), the present work deals especially with the influence of shell ballasting during backfilling on the results obtained in the operational phase, that is, under vehicular moving load. The term ballasting, used above, is meant for the additional load exerted on the shell during backfilling to obtain a favourable prestressing effect. In practice, concrete slabs can be placed on the shell to limit excessive uplift. The results derived from strain gauge measurements are used to verify the results of the finite element (FE) analysis. It is demonstrated that the agreement between measurement and modelling results can be improved by applying in the model ballasting of the shell at the backfilling stage.

The structure of the paper is as follows. After introduction, the soil-steel bridge in Ostróda, Poland is 

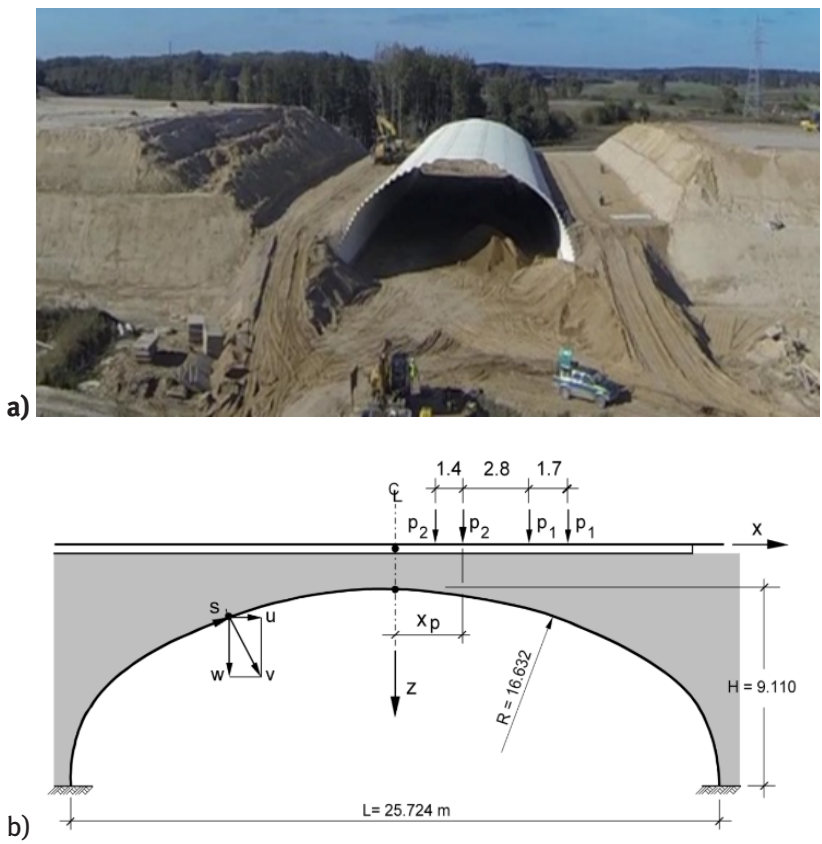

Figure 1: Photograph of the shell during backfilling (a) and geometry of its longitudinal cross section (b).

described in Section 2. Section 3 concerns the calculation of shell displacements from unit strain measurements. First, the algorithm is formulated, and then the results obtained for the bridge in Ostróda are presented and discussed. Subsequently, a numerical analysis of the object's deformation is taken into account. The results for two cases, without ballasting and with properly calibrated ballasting of the shell, are presented and discussed. The paper ends with a brief summary and conclusions.

\section{Soil-steel bridge in Ostróda}

All the analyses and measurement results presented in the paper refer to the bridge structure in Ostróda, Poland along the national road No. 16 Grudziądz-Olsztyn at $\mathrm{km} 17+983.55$ and along the route of collective roads. This engineering object provides a passage over a wildlife migration route and a local road. Four two-lane carriageways, separated by median strips, contribute to the large width of the bridge, which is equal to $B_{t}=61.82 \mathrm{~m}$ at the crest and $B_{b}=95.70 \mathrm{~m}$ at the base of the embankment. The geometry of the corrugated steel sheet is technically denoted as UC $500 \times 237 \times 9.65$, which represents the UltraCor type with the corrugation parameters: length $a=500 \mathrm{~mm}$, height $f=237 \mathrm{~mm}$ and sheet thickness $t=$ $9.65 \mathrm{~mm}$. The structure with a span of $L=25.724 \mathrm{~m}$ is the largest object of this type in Europe. Upon completion of

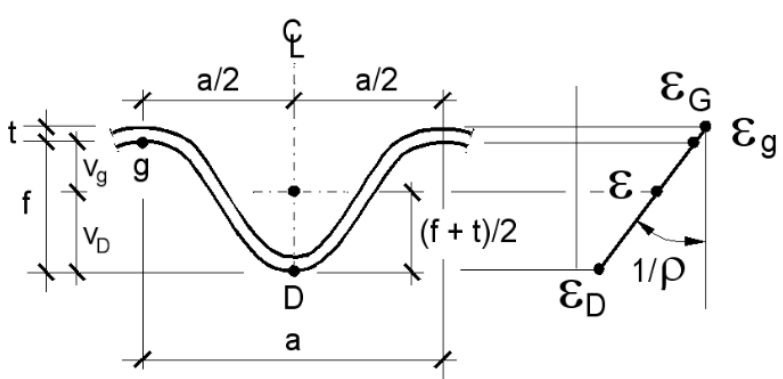

Figure 2: Cross section of the circumferential band of the shell.

construction in 2017, it was also the largest in the world (Sobótka and Machelski, 2016). A photograph of the shell during backfilling and a longitudinal section of the bridge are shown in Fig. 1. Geometry of the shell corrugation in a cross section is presented in Fig. 2.

\section{Calculation of shell displacements from unit strain measurements}

\subsection{Problem formulation}

In soil-steel structure analyses, corrugated sheets are usually modelled as orthotropic shells or curvilinear beams (in 2D). It is also necessary to consider the other structural components: the backfill (laid layer by layer symmetrically on both sides of the shell and compacted), the road surface and the contact zone between the shell and the backfill. As the structure can withstand the load only when assembled together, all these elements should be taken into account. The considerations presented in this paper are carried out assuming a 2D model with the shell modelled as a curvilinear beam. A calculation algorithm to determine displacement utilises strain measurements recorded on the actual bridge structure. The classical Mohr integral scheme, commonly used to calculate the displacements of beam or frame structures, is used for this purpose. The displacement of any shell point in an arbitrary direction $r$ can be determined from the formula:

$$
r=\frac{1}{E I} \int M_{p} M_{r} d s+\frac{1}{E A} \int N_{p} N_{r} d s,
$$

where the internal forces (i.e. bending moments $M$ and the axial forces $N$ ) with the subscript $p$ are the result of the vehicular load exerted on the upper surface of the object and the internal forces with the subscript $r$ are 


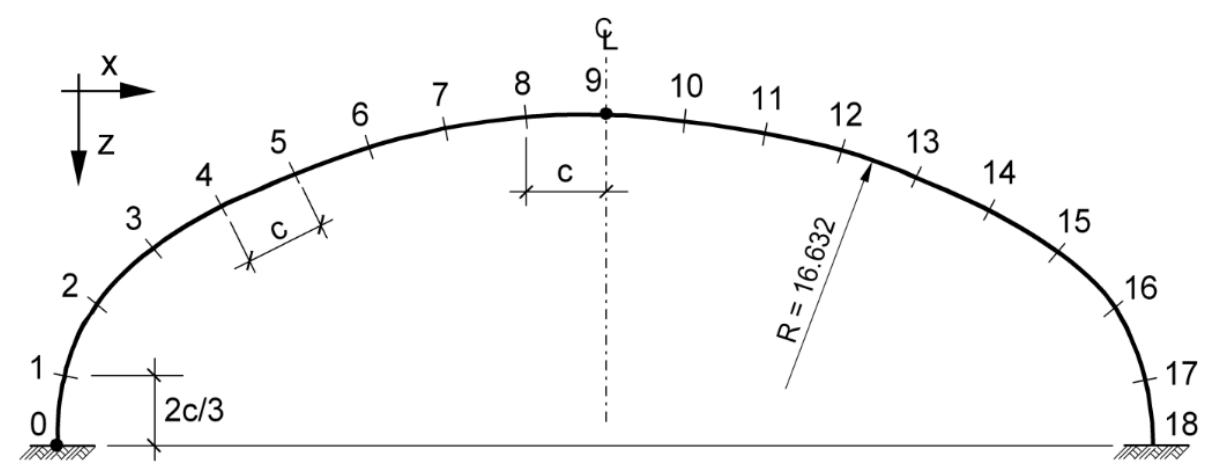

Figure 3: Location of measurement points along the circumferential section of the shell.

the result of the unit load applied at the location of the calculated displacement, consistent with the direction of the latter. Both kinds of internal forces are related to the axis of the curvilinear beam member, denoted as $s$ (see Fig. 1b). Integration takes place throughout the length of the beam. Since the geometrical and material parameters of the shell are constant, the stiffnesses $E I$ and $E A$ can be written before the integral. The next step is to replace the internal forces $M_{p}$ and $N_{p}$ with the measured strain values. Taking into account the geometric relations shown in Fig. 2, according to the Euler-Bernoulli beam theory, equation (1) can be transformed into the following form:

$$
r=\int \frac{\varepsilon_{g}-\varepsilon_{D}}{f} M_{r} d s+\int \varepsilon \cdot N_{r} d s,
$$

where $\varepsilon_{g}$ and $\varepsilon_{D}$ are the unit strains measured at the points g and D, respectively (see Fig. 2), and $\varepsilon$ denotes the unit strain in the inertia axis that must be linearly interpolated from $\varepsilon_{g}$ and $\varepsilon_{D}$ as shown in Fig. 2. The quantities: $\varepsilon_{g}$ and $\varepsilon_{D}$ contain information on the actual mechanical response of the object to the load, including the interaction between the structural components: shell, backfill and pavement. At the same time, for the determination of $M_{r}$ and $N_{r}$, it is sufficient to consider the shell as an independent structure in the form of a curvilinear beam, which greatly simplifies the analysis. Since the values of $\varepsilon_{g}$ and $\varepsilon_{D}$ are measured at discrete points in the shell, a dense grid of measurement points is required to use the proposed algorithm. The measurements can then be extrapolated to make the integration possible. This allows one to reduce the model of a structure to a circumferential section of the shell, that is, curvilinear 2D beam.

\subsection{Real object example}

The considerations presented here are based on the results of an on-site loading test of the bridge in Ostróda.
The test was carried out in a quasi-static manner. Two trucks moving side by side parallel along the road axis (in the plane of the circumferential section of the corrugated shell) constituted the load, as shown in Fig. 1b. The forces transmitted to the structure from each of the front twin axles and the rear twin axles were equal to $P_{1}=60 \mathrm{kN}$ and $P_{2}=100 \mathrm{kN}$, respectively. Hence, the weight of the vehicle was $P=320 \mathrm{kN}$ (a mass of $32 \mathrm{t}$ ). The total load produced by the two trucks was $640 \mathrm{kN}$. The trucks crossed the bridge, and then without turning back, they returned in reverse gear. Therefore, the configurations of the wheels on the roadway (the forces acting on the bridge) that occurred during the initial crossing were repeated during the return. The position of the vehicles is described by the abscissa $x_{p}$ of the third axle, as shown in Fig. 1b. The trucks moved between predetermined positions: the initial passage started at $x_{p}=-L$ and ended at $x_{p}=1 / 2 \cdot L$, and the return from position $x_{p}=1 / 2 \cdot L$ was stopped at $x_{p}=-3 / 4 \cdot L$. The measurements were taken from 17 pairs of strain gauges located along the circumferential section of the shell, as shown in Fig. 3. The displacements are calculated from equation (2) on the basis of the readings obtained from the strain gauges taken each time the trucks moved by $\Delta x_{p}$ $=1 / 8 \cdot L$. An example graph of the unit strains measured at the position of trucks $x_{p}=0 \mathrm{~m}$ in the initial passage is presented in Fig. 4.

\subsection{Results}

The results of the calculations carried out according to the algorithm described in Section 3 are presented below. Figures 5-7 present the calculation results in the form of displacement versus vehicles position charts for three selected points on the shell, that is, 6, 9 and 12 (according to Fig. 3). The plots illustrate the changes of displacement in both directions, that is, horizontal and vertical. 


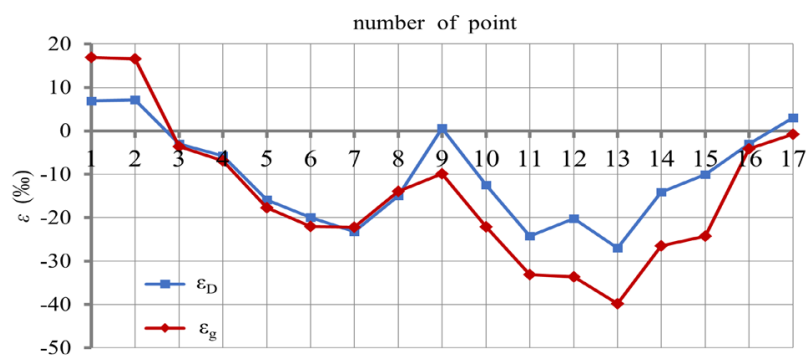

Figure 4: Plot of measured unit strains $\varepsilon_{g}$ and $\varepsilon_{D}$ for $x_{p}=0 \mathrm{~m}$ in the initial passage.

a)
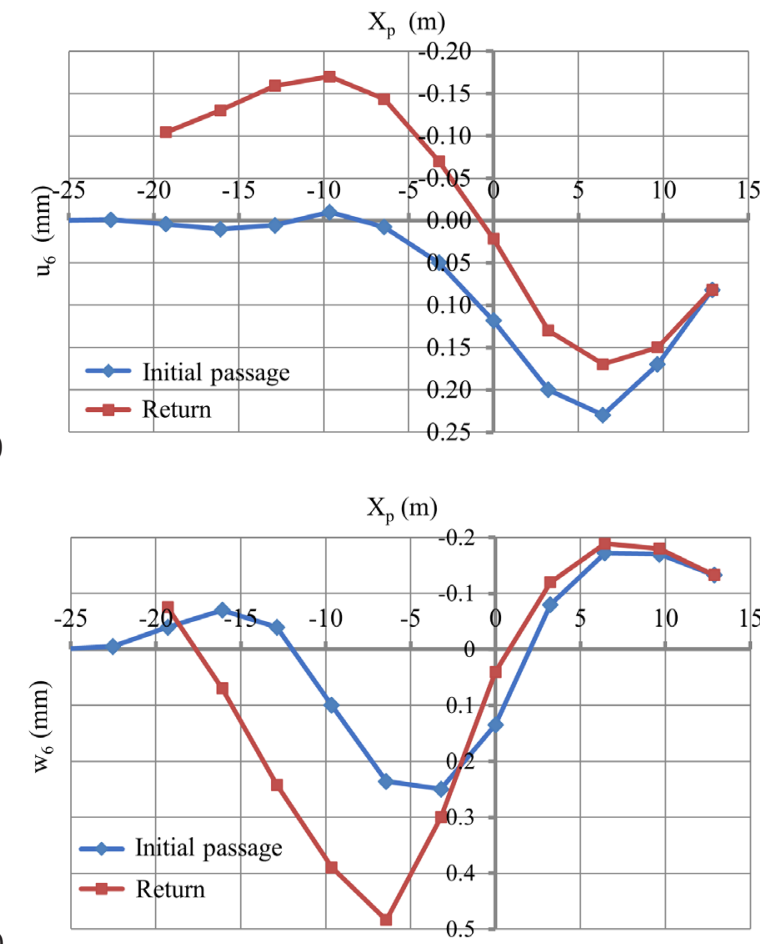

b)

Figure 5: Horizontal (a) and vertical (b) displacement of point 6 during the loading test.

\subsection{Discussion}

A beneficial feature of the shell behaviour is its tendency to restore the initial state of deformation, that is, the zero displacement after a full load cycle (Machelski, 2014). This attribute is observed in many situations, most commonly for the vertical displacement of the shell crown point (Sobótka and Machelski, 2016). However, for other points on the shell, residual displacements are a common result (Sobótka, 2014; Machelski, 2014). This situation is also shown in Figs 5-7. The results obtained using the proposed algorithm exhibit the hysteresis effect. Despite the same

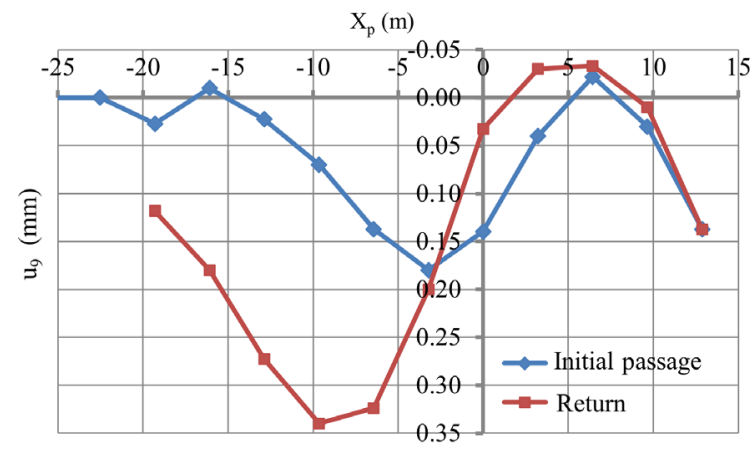

a)

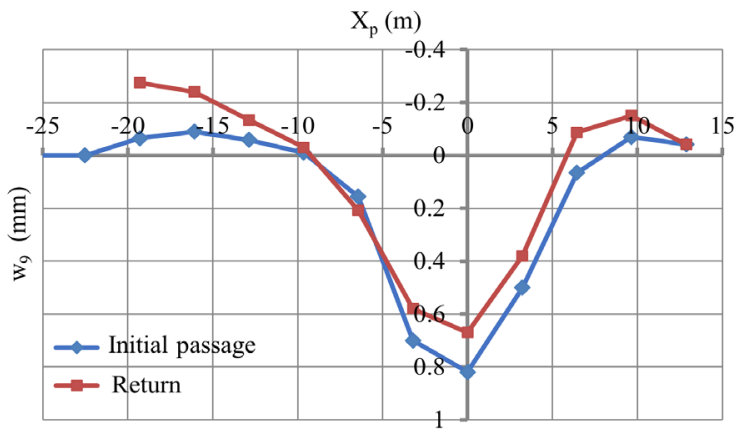

b)

Figure 6: Horizontal (a) and vertical (b) displacement of point 9 during the loading test.

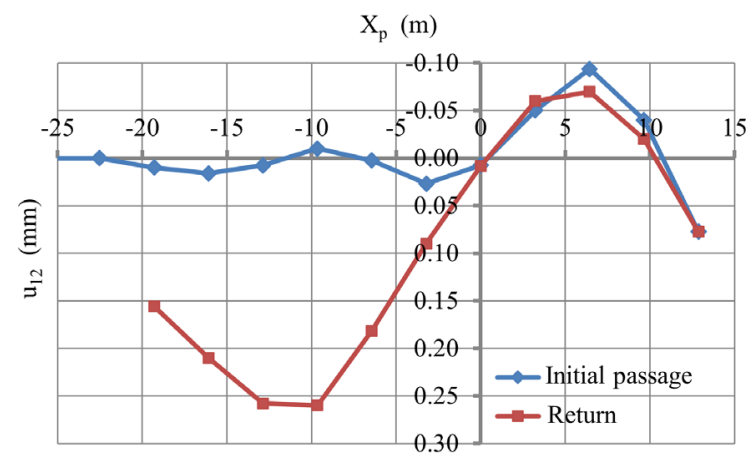

a)

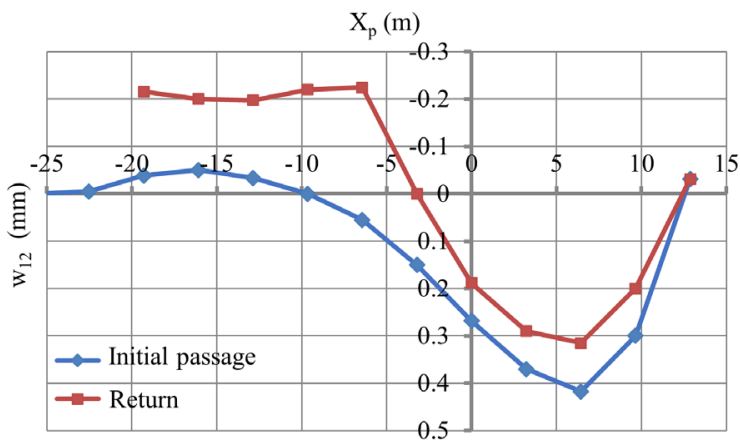

Figure 7: Horizontal (a) and vertical (b) displacement of point 12 during the loading test. 
locations and values of the load in the initial passage and return, the values of displacements are distinctly different. In a qualitative sense, this phenomenon is identical to those analysed in other studies (Eydżba et al., 2017; Sobótka, 2014; Sobótka and Łydżba, 2019; Machelski, 2014; Sobótka and Machelski, 2016).

\section{Numerical analysis of shell deformation}

As a consequence of the continuous development of computers' capabilities, allowing the creation of complex models of engineering structures, it becomes possible to reliably reproduce their geometry (Elshimi et al., 2014) and mechanical behaviour (Eydżba et al., 2017; Sobótka, 2014; Sobótka and Łydżba, 2019; Sobótka and Machelski, 2016). This often requires the use of as many FE elements as several hundred thousand (Mellat et al., 2014). At the same time, attempts are made to simplify the model without reducing the accuracy of the calculations, which is desirable from the view of design practice of engineers. Many authors use 2D models, which is a significant simplification since the load and the mechanical behaviour (deformation) of bridges are inherently three dimensional (3D). Despite this, the 2D modelling of soilsteel bridges has shown to reflect the complex behaviour of real objects, accurately enough for engineering applications (Sobótka and Łydżba, 2019).

Despite the seemingly simple construction of flexible soil-steel bridges, their design and modelling are beset with numerous difficulties. Too simplistic models do not satisfactorily describe the behaviour of buried corrugated arches which, unlike rigid structures, exhibit nonlinear characteristics, for example, the hysteresis effect (Machelski, 2014; Sobótka and Machelski, 2016). However, the analyses presented in Łydżba et al. (2017), Sobótka (2014), Sobótka and Eydżba (2019) and Sobótka and Machelski (2016) indicate that the behaviour of the soil shell structures can be modelled with sufficient accuracy for engineering applications, provided that several conditions are met. In terms of determining the response of the structure to moving loads (such as displacements or internal forces in the shell), the following practical conclusions concerning detailed modelling techniques can be drawn from the research published so far:

- The behaviour of soil-steel structures under live loads is affected by the friction in the soil-steel contact. Therefore, the frictional interface between the shell elements and the backfill should be included in the numerical model (Sobótka, 2014; Sobótka and Łydżba, 2019).

- In order to obtain good agreement (in both quantitative and qualitative terms) between simulation and measurement results, the backfill soil should be assumed to be an elastic-plastic medium. Furthermore, it was demonstrated in Sobótka and Eydżba (2019) that taking into account the so-called apparent cohesion occurring in a partially saturated soil was helpful in calibrating the parameters of the Mohr-Coulomb model for backfill soil.

- By taking staged backfilling into account through the direct modelling of the placement of successive layers (during the construction stage), one can reproduce the effect of shell prestressing. This also applies to the simulation of the behaviour of the completed bridge under the moving loads transmitted from moving vehicles (Sobótka and Łydżba, 2019).

In this paper, special attention is paid to the last of the above points. In particular, a simple method is proposed to take into account shell ballasting during backfilling.

\subsection{Model formulation}

Numerical computations were performed using ZSoil software based on the FE method (Zimmermann et al., 2016). The structure was modelled as a $2 \mathrm{D}$ problem in plane strain. The geometry and the FE mesh adopted in the numerical model are shown in Fig. 8. The simulations were carried out taking into account the staged laying of backfill (24 layers in the numerical model). Furthermore, a surface load was applied to each layer after its activation, which simulated in a simplified manner the load related to the actual soil compaction process. The load was symmetrical with respect to the vertical axis of the shell. The strip loads of $50 \mathrm{kPa}$ on both sides of the shell were moved towards the latter in three stages. The load was not applied in the immediate vicinity of the shell within a distance of $1.0 \mathrm{~m}$. The compaction load at a selected model phase, corresponding to the laying of the 14th layer, is shown in Fig. 9.

For soil (backfill) modelling, 2D enhanced assumed strain (EAS) FEs were used. The elastic-perfectly plastic Mohr-Coulomb constitutive model was adopted. Parameters were estimated using local correlations based on the type of soil used for backfilling (coarse sand with gravel), assuming the value of density index $I_{D}=0.8$. The value of cohesion was slightly increased to ensure the numerical stability of the model. Furthermore, Sobótka 


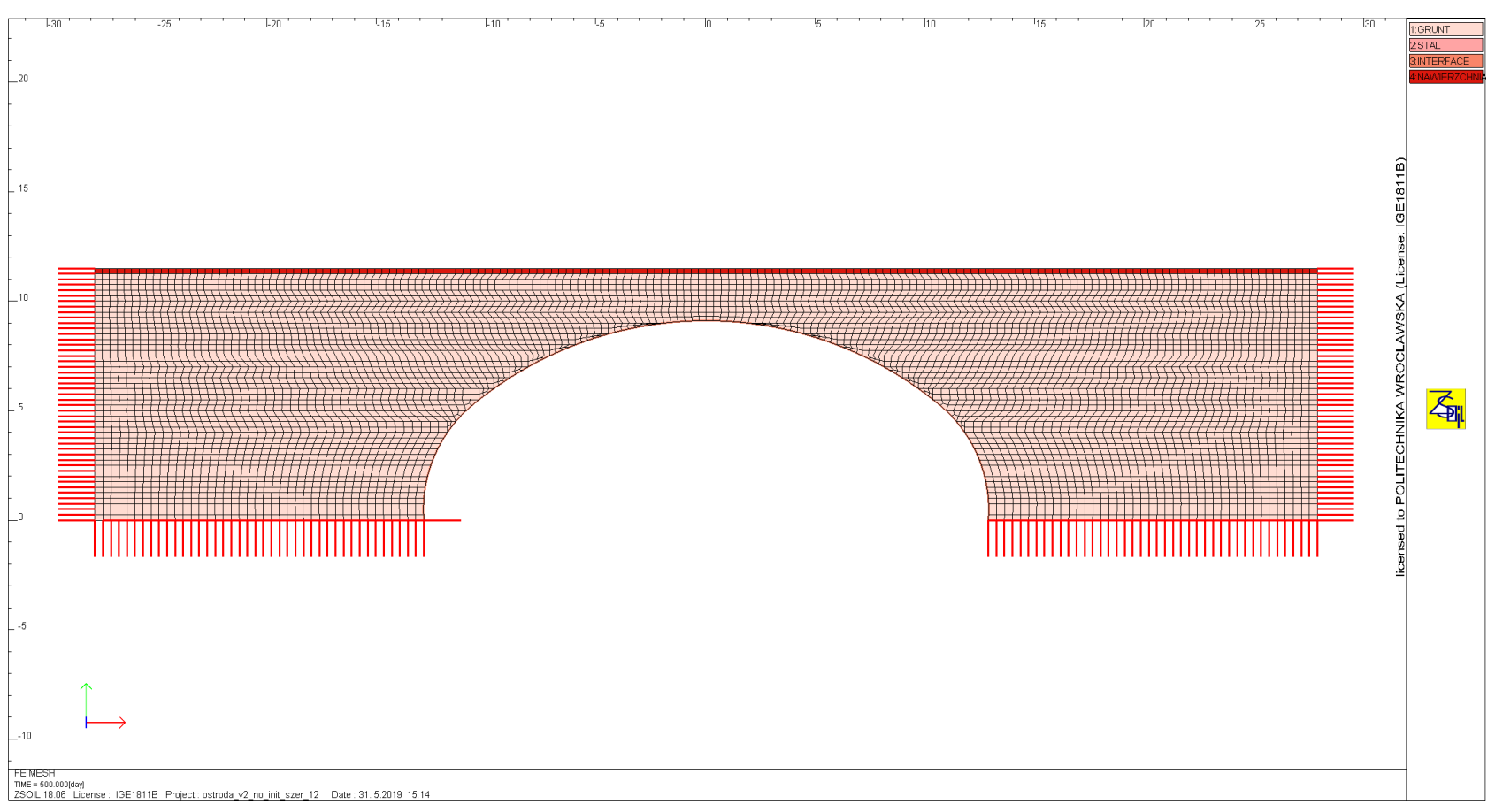

Figure 8: Geometry and finite element mesh adopted in the numerical model.

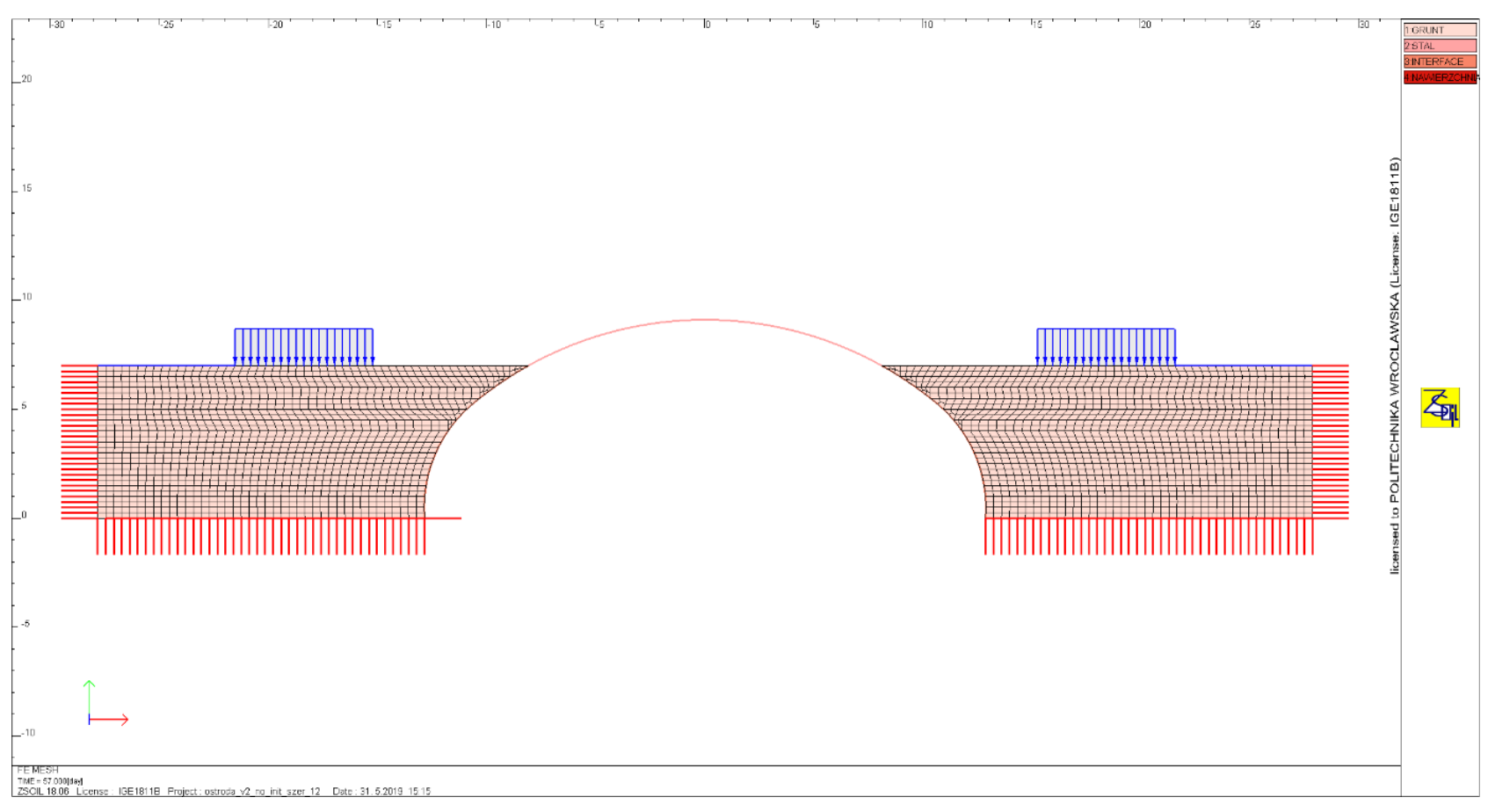

Figure 9: Selected phase of backfilling.

and Łydżba (2019) suggest such an increase due to the so-called apparent cohesion, which is present in partially saturated soils. The assumed unassociated plastic flow rule was described by a dilatancy angle determined according to the ZSoil documentation (Zimmermann et al., 2016):

$$
\psi=\max \left(0.1 \cdot \varphi, \varphi-25^{\circ}\right)
$$


where $\psi$ is the dilatancy angle and $\varphi$ the friction angle. Linear elastic beam elements were used to model the corrugated sheet. The material parameters used in the computations are shown in Table 1.

The contact zone between the soil and the steel sheet was modelled using contact elements whose maximum tangential stress is limited by the Coulomb condition:

$$
\left|\tau_{f}\right| \leq a+\sigma \tan \delta
$$

where adhesion $a=0$, friction angle $\delta=0.6 \varphi$ and $\varphi$ is the friction angle of the adjacent soil. The pavement on the road was modelled as a 0.25 -m-thick layer of $2 \mathrm{D}$ linear elastic FEs with the following averaged parameters: Young's modulus $E_{p}=5000 \mathrm{MPa}$, Poisson ratio $v_{p}=0.3$ and weight $\gamma_{p}=20 \mathrm{kN} / \mathrm{m}^{3}$. The vehicle load consisted of a set of concentrated forces applied to the nodes of the upper edge of the model (the road surface) and was related to the unit width in the direction perpendicular to the 2D plane of the problem. Vehicle movement was simulated, using a quasi-static approach, as a sequence of consecutive vehicle positions, similar to that presented in tydżba et al. (2017), Sobótka (2014), Sobótka and Łydżba (2019) and Sobótka and Machelski (2016). An example of vehicle load (for the position $x_{p}=1 / 2 \cdot L$ ) is presented in Fig. 10.

The values of reduced forces $P$ were calculated as found in Machelski and Janusz (2017) from the following formula:

$$
P=\frac{Q}{b^{\prime}}
$$

where $Q$ is the value of the force transmitted from the vehicle axle (60 or $100 \mathrm{kN})$ and $b$ the reduced width of the impact of both vehicles. Stresses in the soil decrease with depth due to their 3D distribution. It is impossible to recreate such effects in an explicit manner in a 2D model. Therefore, it was decided to determine impact width $b$ through proper calibration in order to obtain the best convergence between the displacements in the model and the measured values. This width was found to be $b=9 \mathrm{~m}$.

As already mentioned, this study focuses mainly on the analysis of the impact of steel shell backfilling, particularly ballasting, on the displacement under moving loads on the completed structure. Therefore, a parametric analysis was performed to calibrate the model due to the initial deformation of the shell. For this purpose, different levels of shell ballasting were tested by increasing its weight in the backfilling phase. To illustrate the effect of ballasting, the results for two cases are presented: 1) without steel shell ballasting and 2) with ballasting level providing the best fit between model and measurements.
Table 1: Mechanical parameters used in the computations.

\begin{tabular}{ll}
\hline Corrugated steel sheet & \\
\hline Young's modulus & $210,000 \mathrm{MPa}$ \\
Poisson ratio & 0.3 \\
Moment of inertia & $9.05 \bullet 10^{-5} \mathrm{~m}^{4} / \mathrm{m}$ \\
Sectional area & $1.45 \bullet 10^{-2} \mathrm{~m}^{2} / \mathrm{m}$ \\
Unit weight (with ballasting) & $77(3080) \mathrm{kN} / \mathrm{m}^{3}$ \\
\hline Backfill soil & \\
\hline Young's modulus & $150 \mathrm{MPa}$ \\
Poisson ratio & 0.25 \\
Cohesion & $5 \mathrm{kPa}$ \\
Friction angle & $34^{\circ}$ \\
Dilatancy angle & $9^{\circ}$ \\
Unit weight & $19 \mathrm{kN} / \mathrm{m}^{3}$ \\
\hline
\end{tabular}

In the calculations, the ballasting was modelled in a simple way, that is, by increasing the weight of the shell by a certain factor. The value of 40 was determined in the parametric analysis as the one that provides the best fit between the simulation and the real scale test.

\subsection{Results}

The graphs obtained for the vertical displacement of points 6, 9 and 12 located in the shell (see Fig. 3) versus vehicle position are presented in Figs 11-13. The plots show changes in shell displacement caused by the initial and returning passages of the vehicles. Similar to the diagrams in Figs 5-7, the changes in displacements due to vehicle movement are plotted as increments in displacement referred to in the beginning of the test. For easier comparison, the convention already used is continued: the initial passage (from the position $x_{p}=-L$ on the left to the position $x_{p}=1 / 2 \cdot L$ on the right) is marked blue, while the return movement (from the right back to the left, i.e. from $x_{p}=1 / 2 \cdot L$ to $x_{p}=-3 / 4 \cdot L$ ) is marked red. Figures 11-13 present the results for both cases, that is, without ballasting (a) and with ballasting taken into account (b).

\subsection{Discussion}

Figures 11-13 show an apparent influence of shell ballasting during backfilling on the displacement behaviour 


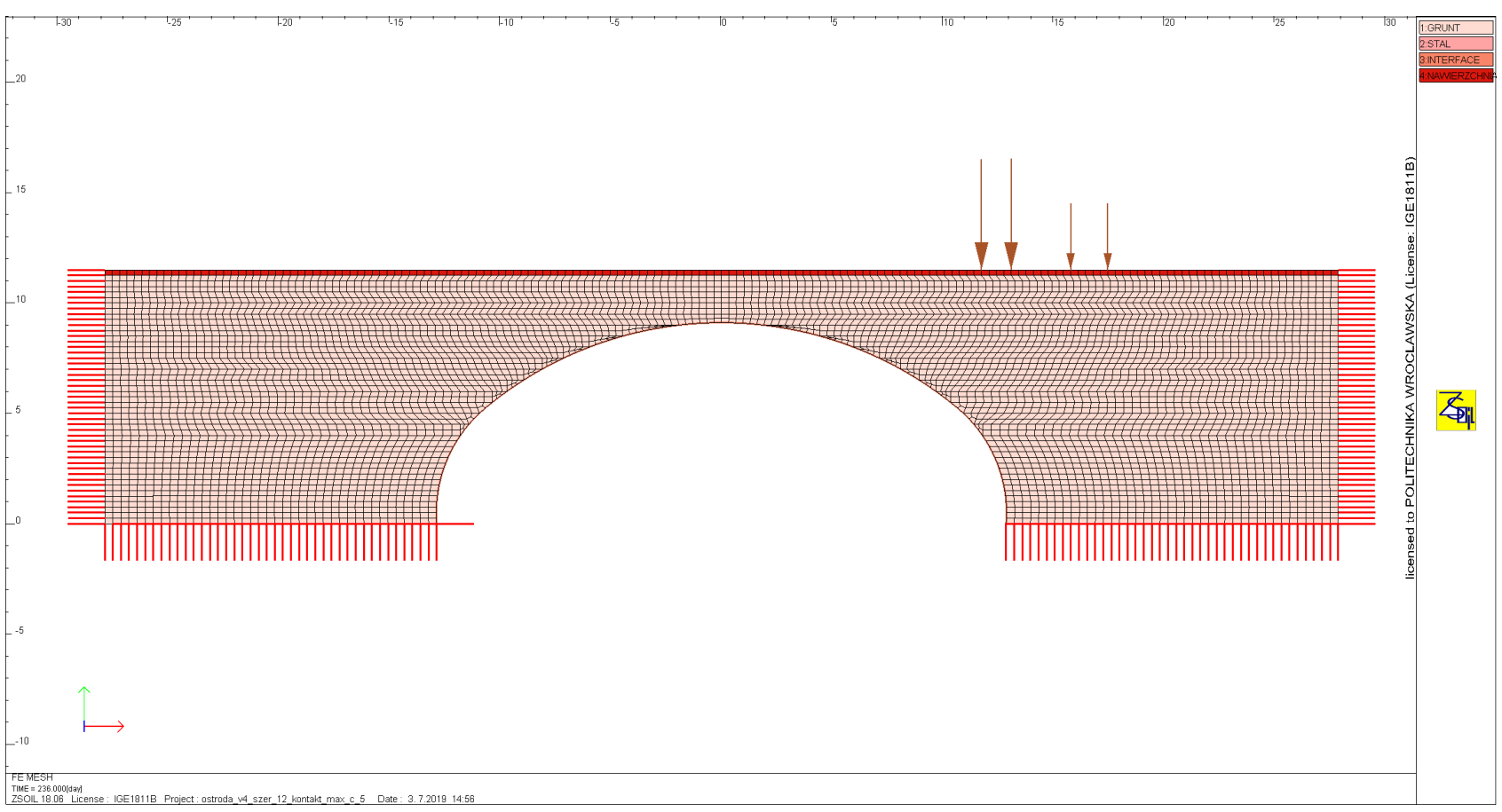

Figure 10: Vehicular loading as a system of nodal forces.
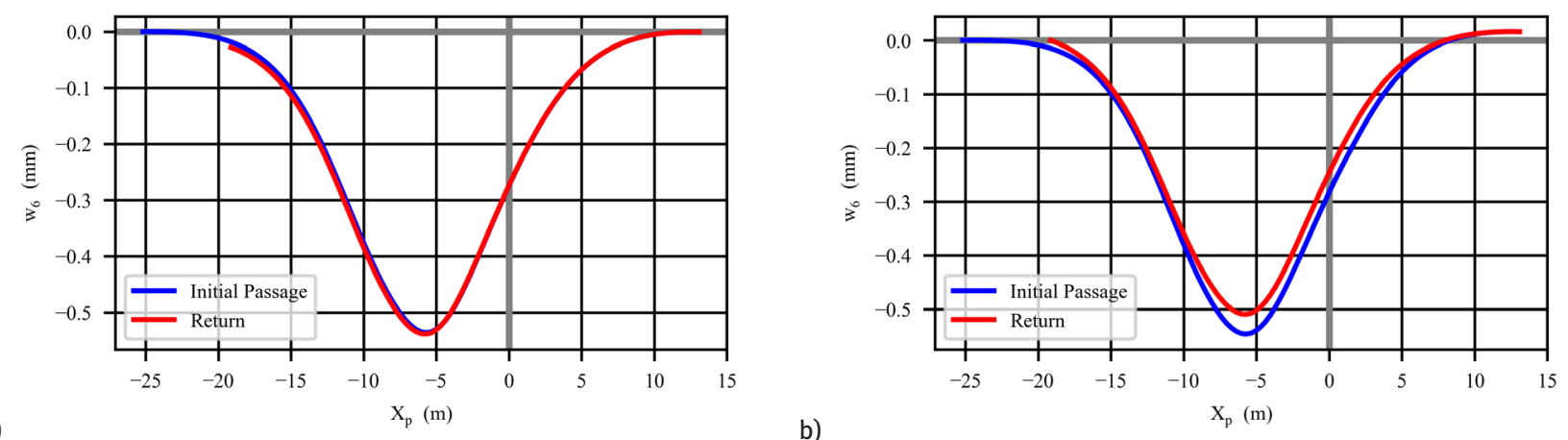

a)

b)

Figure 11: Vertical displacement of point No. 6 during consecutive vehicle crossings: without shell ballasting (a) and with ballasting (b).

under moving loads. Without ballasting, the hysteresis effect is hardly noticeable, whereas after ballasting, the hysteresis loops become much more evident. The vertical displacement graph of point No. 9 shows that the ballasting resulted in a significant improvement in both qualitative and quantitative agreement of the results calculated from the strain gauge measurement and those obtained from the numerical model. The variations in displacement direction, extreme displacement values and corresponding coordinates are consistent with both the primary and returning movement. Such a satisfactory match is not achieved for points 6 and 12. At these points, the maximum downward displacement is slightly overestimated, while the uplift is underestimated.
However, by taking ballasting into account, better compliance between the displacements registered at the beginning and end of the successive vehicle passages is obtained.

In the studies Sobótka and Eydżba (2019) and Sobótka and Machelski (2016), despite the fact that the history of backfilling of the structure was not taken into account, reasonably good agreement between measurements and calculations had been obtained for the displacement of selected control points caused by vehicle movement. However, the behaviour of the Ostróda bridge, considered in this paper, is noticeably different in a qualitative sense. The residual displacement remaining after a full load cycle is oriented upwards. In fact, for point No. 9, the 


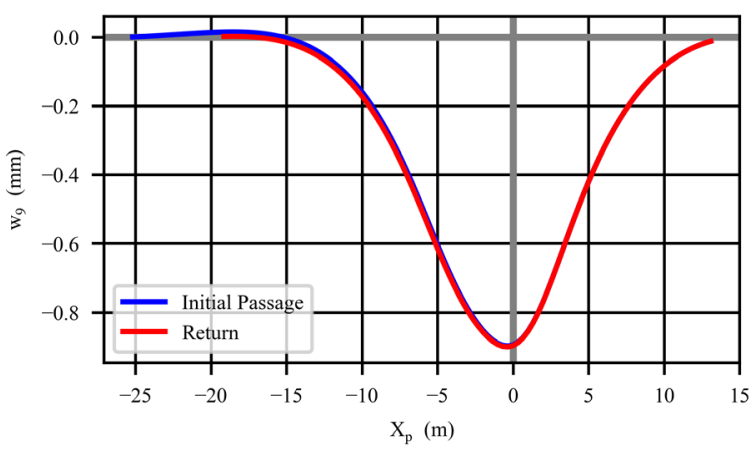

a)

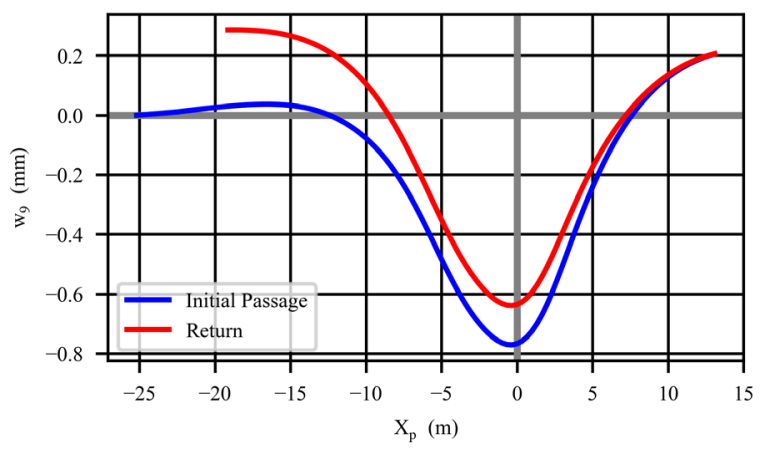

b)

Figure 12: Vertical displacement of point No. 9 during consecutive vehicle crossings: without shell ballasting (a) and with ballasting (b).

part of the plot corresponding to the return passage is entirely above the initial one. It means that the deflection resulting from moving loads reduces with subsequent run. It converges with the results derived from strain gauge measurements (compare Figs $12 \mathrm{~b}$ and $6 \mathrm{~b}$ ). This behaviour is quite opposite to that recorded in the previous research. The results of numerical analysis, presented in this paper, show that such an exceptional behaviour can be reflected in the simulation by accounting for ballasting of the shell during backfilling.

\section{Summary and conclusions}

The effects of loads that change their position, that is, move in a static manner, were examined. The measurement results obtained from a system of strain gauges located in the circumferential section of the shell made of corrugated steel sheets were used to calculate the displacements that describe the deformation of the shell immersed in a soil medium. Through this approach, the solution reflects the actual interaction between the individual components of the structure: the corrugated steel shell, the backfill and the pavement. Furthermore, it plausibly reflects the real material properties, the geometry and the loads in the

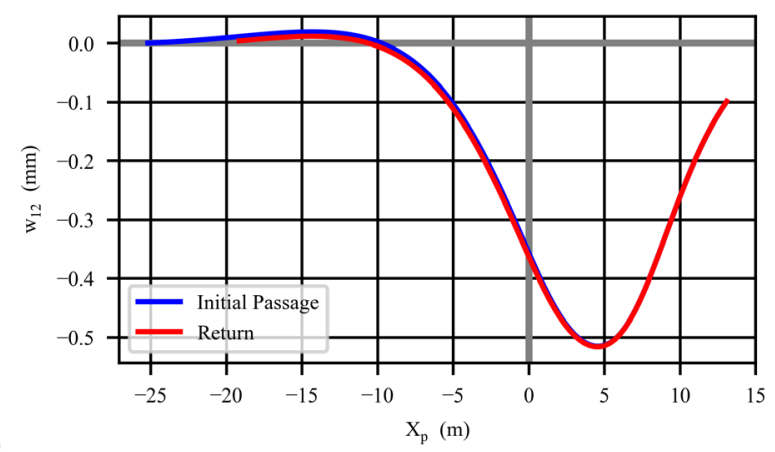

a)

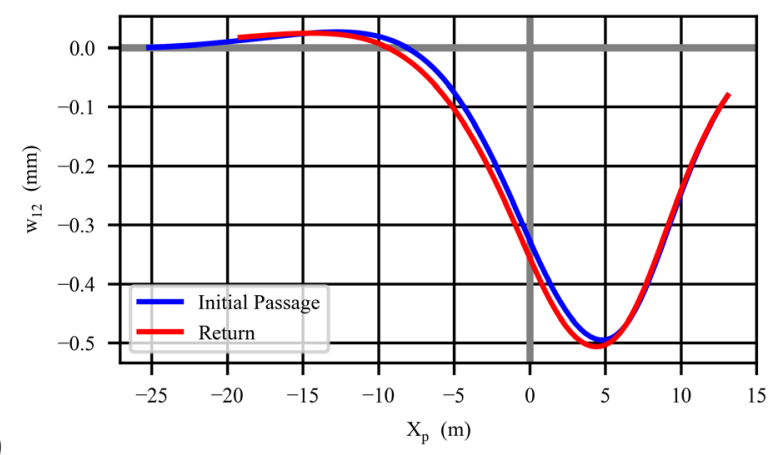

Figure 13: Vertical displacement of point No. 12 during consecutive vehicle crossings: without shell ballasting (a) and with ballasting (b).

actual 3D system. The advantage of the algorithm is the convenient way to determine any displacement component using a simple 2D shell scheme in the form of a curvilinear beam reflecting the shape of the circumferential section of the shell. In addition, there is no need to include the other elements of the bridge in the analysis.

Using the algorithm presented in this paper, one can accurately calculate displacement of the shell on the basis of unit strain measurements. Displacements in any direction can be calculated for any point on the shell. As a result, changes in deformation under loads can be accurately determined. The algorithm was used to calculate the shell deformations during a loading test on site. The results show significant differences in the displacements registered during the passage of the vehicles over the bridge depending on the direction of the movement. This phenomenon, called the hysteresis effect, was previously observed in other soil-steel bridges.

In the second part of this paper, the results of numerical FE analyses are presented. The modelling procedure includes staged construction, that is, backfilling the shell by placing successive soil layers, as well as the loading test with the vehicles moving over the bridge. The practical conclusions concerning the detailed modelling techniques included in the works published so far were 
taken into account. Furthermore, the impact of shell ballasting at the backfill stage on the displacement of the completed object under moving vehicles was investigated in detail. Comparison of results (displacement charts) obtained with and without ballasting indicated that the proposed simplified procedure of shell ballasting during backfilling contributed to improvement in the results in both quantitative and qualitative terms. For reference point 9 (located on the shell crest), both the vertical displacement values and the shapes of its chart are consistent in both approaches presented in this paper. In particular, the successful calibration of the computational model (in terms of shell displacements) is demonstrated.

In summary, the analysed object showed different behaviour trends compared to the previously investigated structures of a similar type in terms of shell displacements under moving loads. Taking into account the ballasting of the shell at the backfilling stage made it possible to obtain a clear improvement in the compliance of the FEM numerical analysis results with the measurement results. Consequently, it was clearly shown that the state of displacement of the shell induced by backfilling can significantly affect the object's response to service live loads.

Funding: The authors received no specific financial support for the research, authorship or publication of this article.

Availability of data and material: Not available.

Code availability: Not available.

Conflict of Interest: All authors declare that they have no conflict of interest.

Ethical approval: This article does not contain any studies with human participants or animals performed by any of the authors.

\section{References}

[1] Abdel-Sayed G, Salib SR. Minimum depth of soil cover above soil-steel bridges. Journal of Geotechnical and Geoenvironmental Engineering. 2002;128(8):672-681.

[2] Barkhordari MA, Abdel-Sayed G. The parameters controlling the strength of soil-steel structures. International Journal of Engineering Science (Tehran). 2001;12(3):77-86.
[3] Bayoglu Flener E. Testing the response of box-type soilsteel structures under static service loads. Journal of Bridge Engineering. 2010;15(1):90-97.

[4] Bayoglu Flener E, Karoumi R. Dynamic testing of a soilsteel composite railway bridge. Engineering structures. 2009;31(12):2803-2811

[5] Brachman RWI, Moore ID, Mak AC. Ultimate limit state of deepcorrugated large-span box culvert. Transportation Research Record. 2010;2201(1):55-61.

[6] Bęben D. Experimental Study on the Dynamic Impacts of Service Train Loads on Corrugated Steel Plate Culvert. J Bridge Eng. 2013;18(4):339-346.

[7] Elshimi TM, Brachman RW, Moore ID. Effect of truck position and multiple truck loading on response of long-span metal culverts. Canadian Geotechnical Journal. 2014;51(2):196-207.

[8] Esmaeili M, Zakeri JA, Abdulrazagh PH. Minimum depth of soil cover above long-span soil-steel railway bridges. International Journal of Advanced Structural Engineering. 2013;5(1):7.

[9] Kunecki B. Field Test and Three-Dimensional Numerical Analysis of Soil-Steel Tunnel during Backfilling. Transportation Research Record. 2014;2462(1):55-60.

[10] Łydżba D, Różański A, Sobótka M, Stefaniuk D, Chudy G, Wróblewski T. Mechanical behaviour of soil-steel structure subjected to live loads and different water conditions. Arch Inst Civ Eng. 2017;23:163-174

[11] Machelski C. Dependence of deformation of soil-shell structure on the direction of load passage. Roads and Bridges 2014;13:223-233.

[12] Machelski C, Antoniszyn G. Load rate of the circumferential sector of soil-steel bridge structures. Archives of Civil and Mechanical engineering. 2005;5(4):85-102.

[13] Machelski C, Janusz L. Application of Results of Test in Developing 2D Model for Soil-Steel Railway Bridges. Conference Transportation Research Board of Nationals Academies, Washington D.C. 2017:70-75.

[14] Maleska T, Bęben D. Behaviour of the soil-steel bridge with different soil cover height under seismic excitations. Bridge Maintenance, Safety, Management, Life-Cycle Sustainability and Innovations. CRC Press; 2021;1801-1808.

[15] Maleska T, Bęben D. Numerical analysis of a soil-steel bridge during backfilling using various shell models. Engineering Structures. 2019;196:109358.

[16] Maleska T, Bęben D, Nowacka J. Seismic vulnerability of a soil-steel composite tunnel-Norway Tolpinrud Railway Tunnel Case Study. Tunnelling and Underground Space Technology. 2021;110: 103808.

[17] Mańko Z, Bęben, D. Research on steel shell of a road bridge made of corrugated plates during backfilling. Journal of Bridge Engineering. 2005;10(5):592-603.

[18] Mellat P, Anderson A, Pettersson L, Karuomi R. Dynamic analysis of a short span soil-steel composite bridge for railways traffic using field measurements and numerical modelling. Eng Struct. 2014;69:49-61.

[19] Pettersson L, Flener EB, Sundquist H. Design of soil-steel composite bridges. Structural Engineering International. 2015;25(2):159-172.

[20] Pittino G, Golser J. Structural plate steel underpasses during backfilling-how to minimize the bending moment. FLAC and Numerical Modeling in Geomechanics. 2006:001-007. 
[21] Sobótka M. Numerical simulation of hysteretic live load effect in soil-steel bridge. Stud Geotech Mech. 2014;36(1):103-109.

[22] Sobótka M. Shape optimization of flexible soil-steel culverts taking non-stationary loads into account. Structures. 2020;23:612-620.

[23] Sobótka M, Łydżba D. Live load effect in soil-steel flexible culvert: role of apparent cohesion of backfill. Eur J Environ Civ Eng. 2019:1-15.

[24] Sobótka M, Machelski C. Hysteretic live load effect in soil-steel structure. Eng Trans. 2016;64(4):493-499.

[25] Taleb B, Moore ID. Metal culvert response to earth loading: performance of two-dimensional analysis. Transportation Research Record. 1999;1656(1):25-36.

[26] Tomala P, Machelski C. Construction of the soil-steel structure with use of UltraCor corrugation (in Polish). Archives of Institute Of Civil Engineering. 2017;24:359-368

[27] Wadi A. Soil-Steel Composite Bridges: Research advances and application. Doctoral dissertation: Kungliga tekniska högskolan; 2019.

[28] Wadi A, Pettersson L, Karoumi R. Flexible culverts in sloping terrain: Numerical simulation of soil loading effects. Eng Struct. 2015;101:111-124.

[29] Wadi A, Pettersson L, Raid K. FEM simulation of a full-scale loading-to-failure test of a corrugated steel culvert. Steel Compos Struct. 2018;27(2):17-227.

[30] Wysokowski A, Janusz L. General conlusions based on the testing of various types of corrugated flexible structures in laboratory in natural scale. Archives of Civil Engineering Institute. 2007:273-286.

[31] Zimmermann T, Truty A, Urbański A, Podleś K. ZSoil user manual. Zace Services; 2016. 